\title{
HOAMROANG SAM PRASAN: The Overture of Three Southern Cultures Concept from The Viewpoint of an Intercultural Composer and Musician
}

\author{
Sinnapa Sarasas \\ Faculty of Music, Silpakorn University, Bangkok, Thailand \\ sinnapas@gmail.com
}

\begin{abstract}
This article examines the process of combining three distinct traditional music cultures in Pattani, Thailand, into one piece of music. The author was the music director of the "Hoamroang Sam Prasan" (Overture: Harmony of the Three). Since the three musical traditions - Nora, Rong Ngeng and Digir Hulu, and Chinese drums ensemble - are similar yet different, the work was both easy and difficult. As someone with long experience in intercultural music, I developed a distinct way to do collaborative work. I seek to ensure musicians contribute their best to the piece, establish bonds of trust to co-operate, so they are willing to share in different ideas and training. The project drew the best from traditional musicians so they could develop new work on their own terms with their own musical abilities in a mode I call "conservative contemporary music." Both artists and audiences could better appreciate the vitality of different musical traditions and their lively interactions more fully.
\end{abstract}

\section{Keywords}

intercultural work - contemporary music - Rong Ngeng music - Digir Hulu music Chinese drum - Nora - Pattani - Thailand 
How to combine different living musical traditions into a single piece of music? This article provides an answer to this question, and suggests an approach to thinking about and working through that problem. It is based on a music project I was involved in from August 2016 to September 2017. In August 2016, I was invited by Master Thammanit Nikomrat, a gifted master of the traditional Nora art form from Songkhla, Thailand to work with him on an intercultural and cross-disciplinary music project that sought to combine traditional Nora music with traditional Chinese drum music and traditional Rong Ngeng and Digir Hulu music into one single piece of music (Nikomrat 2019). This combination sought to embody both the diversity and the interactive harmonies of the above living musical traditions in Pattani, Thailand. Master Thammanit planned to assemble a group of young performers who could play music from Nora, Chinese drums, and Rong Ngeng / Digir Hulu musicians from Decha Pattana Yanukun School in Pattani city, with assistance from local music experts in those traditions. He was inspired for this project of fusing local Pattani musical cultures by the example of the Chinese Goddess Lim Ko Niao (Lin Guniang 林姑娘, literally the "[unmarried] daughter of the Lin family") whose popular shrine is now found on Arnoaru Street in Pattani city. ${ }^{2}$ Lim Ko Niao has been a key deity at the shrine where she is now located since at least the late 19th century. She is known as a healing goddess, and her shrine is the focus of three major celebrations each year, including one held in the second lunar month, which draws many people from the region. These celebrations for the goddess often include performances by the many living musical traditions in southern Thailand, a fact which indicates the diversity of the region's cultural life.

1 The main artist researchers for this project were Assistant Professor Thammanit Nikomrat of Thaksin University in Songkhla and me, Sinnapas Sarasas, from Silapakorn University in Bangkok. This research was done in 2016 and 2017 as part of the umbrella project "Performance Research: Doing Creative Research in Contemporary Thai Performing Arts" run by Professor Pornrat Damrhung (as a TRF Senior Scholar) supported by the Thailand Research Fund Senior Research Scholar Fund 2016 - 2019 (RTA 5980o10). The author would like to thank the two anonymous reviewers of an earlier version of this paper for providing their comments and suggestions. They helped improve the focus of the paper and enabled me to clarify some points.

2 Lim Ko Niao (also spelled Lim Gor Neaw) was the presumed younger sister of the 16th-century Chinese trader and pirate from Chaozhou, Guangdong named Lin Daoqian (林道乾, in Thai ลืมโต๊ะเคียม) who supposedly defected in 1578 to work for Queen Raja Bill (Queen of Blue) of Pattani in Kru Se, which was the capital of the kingdom. Lin Guniang became a well-known goddess for Chaozhou or Teochew people in Siam from the late 19th century and her shrine in Pattani city became more popular from the 195os, with more than dozen shrines opening in Southern Thailand. 
Master Thammanit thus wanted to create a site- and event-specific piece of music at Lim Ko Niao's shrine in Pattani for February 2017 that interwove three key living musical traditions from the area. It would be performed before the main celebrations there in February, as a kind of "Hoamroang" or "overture", before what was expected to be Nora and other performances. To help him realize his goal, Master Thammanit asked if I could join the project as a co-researcher and help create an intercultural piece of music in a contemporary style for this event. We had previously worked together, and he wanted me to help in this project due both to my extensive experience in that kind of work and due to the trust he had in me. My task for developing this "overture" was thus to embody the diverse music cultures of Southern Thailand into a single piece of music. The piece would combine the instruments, musical styles and performers commonly used in those different traditions. It was meant to be performed to open the ceremonies in front of the Lim Ko Niao shrine in Pattani before the main Nora performance was to have begun.

From September to December 2016 we began the project as planned, at first using high school and university student musicians to perform, advised by music masters in each tradition in the first five months of the project. During this first phase, the project developed slowly and unevenly due to little rehearsal time we had-due to the different provinces involved (Songkhla, Pattani, Bangkok), the uneven abilities of the musicians, and the varying degrees of their understanding of the musical traditions we sought to integrate. Nevertheless, we made significant progress toward reaching our goals. This first phase culminated in a work-in-progress performance on December 17, 2016 for artist-advisors and the temple committee leaders from the Lim Ko Niao shrine in Pattani. It was impressive enough to lead to its invitation to perform at the Annual Celebration of the Goddess on February 10, 2017. Although the February performance of the overture with student ensemble at the Shrine was successful, there were some difficulties in arranging times to work with the students, who were preparing for their exams afterwards, so the main artist-researchers decided to move into a new phase in the project. From February 13, they chose to develop the piece further by collaborating with professional Rong Ngeng and Digir Hulu artists in Pattani province and to form an artistic network with them. After communicating for a month and developing bonds of trust for several months thereafter, the ideas for the piece firmed up. An intensive two-day interactive rehearsal period produced a better flow and more internal solidity by mid-August 2017 , and led to the last-minute inclusion of a short original improvisational dance inspired by the overture into the performance. Further intensive rehearsals at Chulalongkorn University a week later preceded performances on August 20 and 21 at the Sodsai Pantoomkomol 
Centre for Dramatic Arts and then at the Thailand Research Fund's conference in Bangkok held from August 22 to 26, 2017.

Although much was learned from work done in the first phase of the project ending on February 10, the second phase of the project from February to August 2017 was more fruitful, and it helped to confirm that local professional artists could work well together with trust and confidence, and produced new harmonies among themselves. The new version of the overture that emerged in this second phase of the project further produced its own special meaning of unity in diversity with the new dance in it. It marked a new mode of intercultural collaboration among these three local cultures from southern Thailand through the arts.

The Meanings of "Hoamroang" and "Overture"

Before discussing the working process used in more detail, it is important to first explore the meanings of the terms "Hoamroang" and "overture", since there still are some misunderstandings about their meanings and significance. There is only one suitable word to translate the Thai word "Hoamroang" (โหมโรง) into English and that is "overture". Nicholas Temperley (2019) defines "overture" as follows, noting two basic meanings: "A piece of music of moderate length, either introducing a dramatic work or intended for concert performance.... In modern usage the word denotes, first, a substantial piece of orchestral music designed to precede a full-length dramatic work.... It may be in one or more sections, and may or may not come to a full close before the drama begins."3 "Overture" and "Hoamroang" thus mean slightly different things, but both listeners and musicians do not always properly distinguish the two words. ${ }^{4}$ Most people think that "overture" is a short instrumental music played before the curtain goes up to begin a show like a ballet, play, opera, or musical. But both "Hoamroang"

3 Nicholas Temperley, "Overture," Grove Music Online https:/www.oxfordmusiconline.com/ grovemusic/view/10.1093/gmo/978156159263o.oo1.0oo1/omo-978156159263o-e-ooooo2o616 [accessed November 21, 2019]. The Oxford Living Dictionary defines it: " 2 • An orchestral piece at the beginning of an opera, play, etc. 'the overture to Mozart's 'Don Giovanni'; Overture and Incidental Music for 'A Midsummer Night's Dream" or "An independent orchestral composition in one movement. 'Tchaikovsky's ' 1812 Overture.".

4 "Hoamroang" (Royal Institute 2011) $\cdot n$. the music performed before the main show begins $\cdot n$. the music that functions as an introduction of the main performance, calling out to audience that the show is about to start. The music has various types according to the nature of the performance or the show that follows e.g. Evening Hoamroang, Morning Hoamroang, Semon Hoamroang, Stage Play Hoamroang, Sepa Hoamroang. 
and "Overture" could be of varied lengths and plays various functions. Thai "Hoamroang" has a wide range of lengths-from 2 minutes to more than half a day, but they most often range between two and ten minutes, like in "Morning Hoamrong" and "Evening Hoamroang." The length of a typical Western overture is normally shorter, about four minutes, but sometimes lasting more than 10 minutes, such as the "Flying Dutchman Overture" by Richard Wagner which is 10:28 long and the "William Tell Overture" by Gioacchino Rossini which is 12:07 long.

Most people likewise think that an overture is a composition that contains the musical themes of the larger work that follows it, while also being a pleasant piece of music in a moderate tempo. But some overtures do not follow these common expectations, again like Wagner's "Flying Dutchman Overture," which contains the full thrill of the larger composition. Some overtures could also be performed separately as what is called a "concert overture."

Given this background, the "Hoamroang Sam Prasan" we developed had two characteristics and functions. The first function was as a "Hoamroang" which would call on those near the Goddess' shrine to come and settle down for the festival, which in this case was at the start of three-day celebration of the goddess before her shrine. The second function was to act like a mini-concert, as a kind of unique musical performance, not one which narrated the romantic story of the Goddess Lim Ko Niao. The work we created thus stands on its own as a unique, separate composition and does not function as "overture" which would introduce the themes or musical ideas that would appear in some later show of the Goddess's festival. Moreover, the "Hoamroang Sam Prasan" is quite long, lasting 18:30, and has a unique colorful character, as a piece of narrative music, making it much closer to what some would call a "concert overture".

Master Thammanit long wanted to create a music piece that could blend the three Southern cultures into a single Hoamroang piece of music for the Nora performance in celebration of Goddess Lim Ko Niao in Pattani. The three music cultures he wanted to combine were 1). Nora, his own tradition (which he saw as Theravadin Buddhist) 2). Chinese drums ensemble (which he saw as Chinese Mahayana Buddhist), and 3). Rong Ngeng and Digir Hulu (which he saw as Thai-Malayu Muslim) (Binson 2011; Pidokrat 2011).

5 This is often a one-movement orchestral piece, typically with a descriptive or evocative title which could use the sonata form, or work as a symphonic-poem. An early work in the genre would be Mendelssohn's “The Hebrides", and for later examples, there are Elgar's "Cockaigne" and "In the South.". 
It is important to take care when dealing with different cultures, including musical cultures. All musical forms are embedded in cultures, and in this case all three forms are part of complex folk cultures. Folk music works like twoedged sword. On the one hand, its music is open to do including many things, yet at the same time there are expectations, traditions, norms, lore, and ways of life to understand before seeking to work with the different traditions together.

Elements of each musical culture needs to be carefully studied in detail, beginning with their instruments. The main instruments of the ensemble of each type of music we used were as follows:

Nora: Pi (Thai oboe), Nora drums, Tub (small drum), Gong, Ching (hand cymbals).

Chinese drums: Drums of different sizes, Pi, flat cymbals of different sizes. Rong Ngeng \& Hulu: Rammana, drums of different sizes, violin and accordion.

These three music cultures have one unique thing in common, namely their rhythmic characteristics and patterns, so this is what we started working with. The main instruments for the musical piece were to be drums, and the life, rhythms, colors, sonic texture, and contours for the entire piece were to be determined according to those of the drums. A second similarity in the music cultures is a similar way of singing, where a single vocalist sings alone, after which the chorus responds, done in a call-response style, with a mini-refrain sung before the next mini-verse of the soloist. This feature would also be part of this new piece.

\section{Musical Interpretation}

I started developing my interpretation for the Hoamroang by reading the legends of the Goddess Lim Ko Niao, using different versions available. From all the variants I read, I found that the Goddess was a fearless, generous and honest figure, one whose focus and determination led her to remain steadfast in reaching her goals, so she would not change her mind if she decided to do something. Although most versions of her legend end in her suicide by hanging herself from a cashew nut tree, I also saw in her a brave character who would engage and take responsibility for her actions, so much so that her powers continued and even grew after her death. The outstanding charisma of the Goddess Lim Ko Niao is that of a female warrior with unwavering determination and great kindness toward people. This became the basis of our 
interpretation. The female warrior idea was seen in her strength of mind, valiance and ferocity in battles-all to be shown through the drum work while her great kindness - the gentleness of a woman - would be portrayed by the pitched instruments like the Nora Pi and the Rong Ngeng violin. Once we embedded this interpretation into the instrumentation, we next developed the characterization of the musical instruments in more detail. So the instruments became like actors portraying different roles or characters, thus leading to certain choices of music, and the writing of lyrics in the Hoamroang to relate both to the three musical traditions and to the overture form.

"Hoamroang Sam Prasan": Conservative Contemporary Music

Although working in this approach made it difficult to create a contemporary-traditional music composition, it did permit creating a uniqueness in the piece tied to a common theme. And even if the musical elements (i.e., musicians and musical instruments) were the same, each performance would always be unique, never a repetition of the same. This made the "Hoamroang Sam Prasan" a kind of music which is both contemporary and conservative, in that it provided new spaces for the different musical traditions to show themselves on their own terms, with their own distinct musicality, while also giving them opportunities to show fresh and unexpected interactions with one another.

The piece would always be "live," be a new take, each time it was performed. All who were involved always had the benefit of new experiences, new knowledge, new learning they could bring to each performance. When it comes to traditional arts, although most people would not choose it, it must always be difficult to deal with if we really care for their artistic sensibility and cultural specificity. We should not trade these things for our comfort. There is always a risk of destroying our own culture if we do so. This composition was a product of blending traditional music of three Southern cultures in Thailand without turning any of their original characteristics into a Western tone or sound. It remained a unique part of southern Thai culture.

In what follows, I will first discuss the role of characterization, musicality and musical contour that I used as general innovative techniques to shape the musical piece to the goal of its performance. I then discuss how these techniques were part of the working processes from the First Phase (from Sept. 2016 to Feb. 2017) to the Second Phase (from Feb. to Aug. 2017) of the project, before providing a brief conclusion.

Characterization in music is similar to "interpretation" or "tee bot" (role-playing) in traditional Thai performing arts. This practice assigns a role or roles to 
each musician or a group of musicians, asking them to portray a character or several characters, varying according to the music, instruments, their skills, experiences, curiosity and creativity. Musicians use their characterization or role-playing with instruments to produce new tones, new sounds, new tricks in playing, and music effects from their familiar instruments by imagining particular scenes, actions, or atmospheres in their musical movement. This mode of music-making is not a normal way of composing, especially in traditional music.

Using characterization in this way is useful to both create new music and to add life to the composition by role-playing through musicality, which permit imaginations and emotions to flow through the sounds and silence, in pulses and pauses, in new pacing, new breathing, new phrasing. ${ }^{6}$ Musicians use musicality to become like actors, in a way, who act through using their instruments, their voices, and even their silences in new ways which are suitable to the music being played.

Characterization was done by using musical instruments in the following ways:

- $\quad$ The Nora pi and Rong Ngeng accordion are used to characterize a beautiful woman with gentleness and kindness; and sometimes with sadness

- $\quad$ The Chinese drums characterize a female warrior, in her valiance, in her battles (musicians act as warriors)

- $\quad$ Other Nora drums and percussion instruments characterize the ongoing journey and strong determination of the woman. (The musicians act as painters giving colors and texture to the story)

- The Hulu's Rammanas and percussion instruments characterize the liveliness and beauty of the people. (These musicians represent the people) Creating the musical contour or musicscape is the "landscape" or layout of the whole piece of music. A good musical contour makes the music alive, colorful, and interesting - e.g. through different and similar instruments, dynamics, tempo changes, different numbers of instruments performing at particular movements, etc.

Since the "Hoamroang Sam Prasarn" aims to be an overture to celebrate the Goddess, the first notes or the first sound of the piece must be stunning

6 "Musicality" in the Oxford English of Dictionary, refers to "1. musical talent or sensitivity: her beautiful, rich tone and innate musicality $\mid$ his compositions reveal an exceptional degree of innate musicality. 2 the quality of having a pleasant sound; melodiousness: the natural musicality of the language." What is "musical" is "1 relating to music: they shared similar musical tastes. ' set to or accompanied by music: an evening of musical entertainment. · fond of or skilled in music" or "2 having a pleasant sound; melodious or tuneful". 
enough to get the attention of the people milling around the venue - which is full of incidental activity and noises - and entice them to come to the stage and take their seats, to prepare to see the performance. The length of the piece depends on the nature of the particular festival, the people present, and the venue. In our initial thinking for this piece, Master Thammanit sought a piece that would be about 10 minutes long.

Analysis of the Music-Making Process and Performances

The analysis of the music-making and performances of the "Hoamroang Sam Prasan" will be divided into a process with two phases. In the First Phase, I worked with the musicians to develop the design, form and flow of the "Hoamroang Sam Prasan". 7 The piece was imagined to consist of four movements: Introduction, Rong Ngeng, Nora and Hulu, Coda. The second phase developed by working with professional Rong Ngeng and Hulu musicians, and added a dance to the performance.

\section{Phase One Rehearsals and Performances at the Shrine of the Goddess}

Musical characteristics of the three cultures. Each of the music ensembles had a different pace in learning to work in a contemporary mode. This was largely due to the different function of its music in each of the three cultures. Nora music, by its nature and function, is more colorful than the others since it works with stage performances tied to folklores and rituals. The music works with the story, the characters, the moods of the characters and scenery. Rong Ngeng music also works with stage performances, but it is mainly used for dances. Its music is beautiful and sweet but lacks in the range and variety of its musical color scheme. The Chinese drums' have a character which is most open to new approaches, including new breathing and new contours for contemporary

7 The musicians in Phase One of the project were: Master Thammanit Nikomrat, Nora vocal, trae, percussion; Kittisak Sa-ahdchinda, Nora drums; Anurak Deekaew, Nora tub, Chinese percussion; Niwat Sae-lim, Nora gong and ching; Chayut Achaiyoung, Nora trae; Sutthipong Chuaynusondhi, Nora pi; Anuwat Kheowjan, Chinese drum; Sahassawas Khongshu, Chinese drum; Viradech Thongkham, Chinese drum; Thares Nawayo, Rong Ngeng accordion; Wiwitchai Phahukul, Rong Ngeng gong; Chakradulya Sopha, Rong Ngeng rammana, percussion; Yongkrit Sainate, Hulu rammana; Hafis Jehmah, Hulu vocal and rammana; Haffahn Jehmah, Hulu rammana. 
work. Its rhythmic patterns are simple but powerful and energetic, but its reliance on percussive instruments makes it easier to improvise and communicate with other cultures. We just added some space for playing with its rhythmic dynamics, like the patterns of crescendo and decrescendo, the space between notes and patterns to the playing, and it sounded contemporary.

Direction and focus. Normally, when there is an event for a musical group to prepare for, traditional musicians gather, lay out the main songs, learn them, and rehearse for a short period of time before going out to perform. They usually act as the live band for dance performances. The musician's mind focuses on playing correctly as rehearsed, and it is not important if there are some imperfect notes. What matters is that the band is performing live, playing in a corner, out of the spotlight. They are not the focus of the performance, the dancers are. But for this project, we needed to develop a different working process for the piece. The musicians were the performers, just like a jazz band or a rock band, so every member of the band had to perform to the best of their ability to give life to the music: they could not hide. There were no dancers (a first), so the musicians had to fill many roles. They represented their own culture; they were to play the roles of the characters in the song; they sang and danced (for the Hulu); and they were to be the story tellers. As such, the musicians were always in the spotlight throughout the performance. This "overture" was itself a music concert and they had to act as the musicians in that concert. But aside from adapting some Western ways to make the musical contour smoother, the musicians first had to adapt to the idea of being concert musicians onstage, too. They had to adapt the way they carried themselves with self-confidence, staying still and focused when they had no parts in the piece, how they projected their energy and feelings to the audience through their music when they were playing, how they kept their focus on the music being performed and how interacted with other members of the band. The sound, the visuals, the energy of the musicians all had to be relatively interconnected and focused on the audience at each moment when the piece was being performed.

\subsection{Phase One Rehearsals}

Working with traditional music and traditional musicians requires some special approaches in rehearsals, especially when there are musicians from various backgrounds, with many are new to both of us, to the other musicians, and to this kind of musical adventure and experimentation. Rehearsals were held for two days each month for several months in the Fall of 2016. We needed time together to get to know each other and to get into each other musical pulseto play music together (any songs will do), to chat, to eat, to drink together, to 
share and experiment some wild ideas, to explore new sounds to make on their own instruments, etc. The diversity of skills and experiences in the ensemble posed some problems of understanding for this kind of work that became clearer over time. Some musicians had done this type of work with us before, but many others were new to the working process. To step into this type of music-making, musicians need to have personal assets and availability. Those who are new to this type of work need time to absorb the idea and explore on their own terms so they can catch up with those who had had experiences before. But they helped each other, with professionals and masters working with students. Yet it was not such a successful working process. There were large gaps between the participants in their discipline, skill-level, experience, and understanding. Most young musicians could not catch up with the professionals, and the music could not come fully alive as desired or hoped for. But since we had time, we were able to develop the piece slowly, bit by bit.

\subsection{Phase One Performances}

On February 10, 2017 the First Phase of the project ended in two performances of "Hoamroang Sam Prasarn" for the festivities at the Lim Gor Neaw shrine in Pattani. The first performance was done to call people to the events to be held at the shrine in the late afternoon. The second performance was done later in the evening in the front of the shrine. Both performances were well-received by ordinary festival goers and the shrine committee leaders. But some of the student performers found it challenging in the previous months to make time for the rehearsals and also prepare for their exams. This helped us realize that we may need to reconfigure the ensemble to continue its work into its next phase.

Phase Two Rehearsals and Final Performances In Bangkok

For the Second Phase of the "Hoamroang Sam Prasarn" project, we met on February 13, 2017 and concentrated on preparing for the final performances in August in Bangkok. We decided to find professional Pattani Rong Ngeng and Hulu bands to replace most of the young musicians in Phase One. Eventually, three young musicians did make to the final phase to perform with the professionals: two young players on Chinese drums and one who played accordion for Rong Ngeng. ${ }^{8}$

8 The musicians in Phase Two of the project were: Thammanit Nikomrat, Nora vocal, trae, percussion; Kittisak Sa-ahdchinda, Nora drums; Anurak Deekaew, Nora tub, Chinese percussion; Narudech Yokthaworn, Chinese vocal, trae; Niwat Sae-lim, Nora pi; Naboon 
Re-casting musicians. The initial idea of master Thammanit Nikomrat led to this cross-cultural composition, using traditional musicians from three Southern cultures with some modern approaches. The musicians' charisma is most vital to the task. For this, the following are most important (Nikomrat 2011):

1. The musicians should be well-grounded and have a high level of knowledge and skills of their own musical culture;

2. The musicians should be broad-minded, understanding, imaginative, adventurous, and curious to explore new and challenging dimensions of music;

3. The musicians should be outstanding in both their technical and musical abilities.

The collaboration for Phase Two was compressed into a short time. The 2017 Spring floods in Southern provinces meant our musicians were unable to move for several weeks. Co-ordinating the group's schedules meant we could only arrange to meet for rehearsals for two rounds. These meeting were crucial however, since the ensemble was quite large and since five members were newcomers ( 3 in Rong Ngeng, 2 in Hulu).

Despite these limitations and potential pitfalls in the process, I was optimistic, and, for some reason, I believed we could manage to work through any problems with only a few rehearsals. These were the reasons for my optimism: 1. The newcomers were professionals who were at the top of their art. We had met them before, even though we had not played with them.

2. They were impressed by our first performance at Thaksin University in Songkhla in December 2016, even though the music performed had attained about only $60 \%$ of its potentiality by the Phase One ensemble. They were already developing new sounds using their own contemporary ideas. They were intrigued and eager to experiment with this approach to their music. The three masters of Rong Ngeng from Pattani offered to teach the young Rong Ngeng accordion player old traditional songs and how to get the accordion to work properly for both a melody and for chords (since we could not find a violinist for Phase One).

3. When asked if they were interested in joining our ensemble for the final presentation at Chulalongkorn University, they were more than willing to say "yes".

Suksri, Nora gong, ching; Anuwat Kiaochan, Chinese drum; Viradech Thongkham, Chinese drum; Sarasit Nilchaisri, Rong Ngeng accordion Sombat Srakhamhang, Rong Ngeng violin; Muhammadtaman E-sor, Rong Ngeng rammana; Thares Nawayo, Rong Ngeng and Hulu gong; Yusoh Umar, Hulu vocal and rammana; Abdultoleh Ali, Hulu rammana. 


\subsection{Phase Two Rehearsals}

The three above reasons provided a good basis for our limited opportunities to work together. I knew by then how to begin working with them, since they possessed the same charisma as my own performing group. They were professional, knowledgeable, good-hearted, curious, and ready for some musical adventures. The work would have had difficulties if we did not have musicians who shared these charismatic characteristics. They have to be understanding and willing to join in the exploration and be ready to have fun together. Even top-notch musicians are no good to the project if they lack these qualities.

The musicians communicated with one another several times during the summer about the project so they had some idea of what they would do and they had started thinking about how to work. But we were only able to schedule two days - August 15-16, 2017 - for full group rehearsals. Given this short length of time, the first day was the most important. Our working process did not center on composing and orchestrating, but on letting the musicians to get to know each other musically. We watched the Phase One final rehearsal video together, briefly discussed the characterization and interpretation of each instrument and movement, and listened to the ideas of the new members. Then we started choosing the traditional Rong Ngeng and Hulu songs to replace those used in Phase One, seeking the same key to use for the accordion and $\mathrm{Pi}$, reshaped the new contour (through bridges, interludes, entries and exits of each movement), and discussed how to do a jam session as "Sam Prasan" in the coda (what the mutual rhythm patterns and songs should be the structure for the jam, how long the coda would be, and how the ending should be).

The new ensemble's members (the new Rong Ngeng and Hulu performers) were very collaborative and enjoyed the musical experiments they did with the Nora musicians. We worked together intensively on August 15 and 16, 2017 at Thaksin University in Songkhla.

In these intense Phase Two rehearsals, Master Thammanit worked as the artistic and music director and musician in one. The work on Day 1 sought to revise the whole composition, re-editing and re-composing the lyrics and the coda to make it a real "harmony of the three" or "Sam Prasan" piece (with a unifying jam session of three Southern cultures - the goal we could not do in Phase One of the project).

By the end of Day 2, we decided to add a solo dance piece to interact with the music in the last movement (which consisted of solo musical pieces of each culture). The music was in good order and their contours were lively. Despite the limited time, at last, we had achieved the three cultures jam in the coda. It was short, but it was indeed a "Sam Prasan" of our three Southern cultures. 
The big difference between the Phase One and Phase Two ensembles is the good proof of the importance of having open-minded and capable musicians. The Phase One musicians consisted of many more rehearsals than Phase Two, but it had only attained about $6 \circ \%$ of what was expected, while Phase Two had achieved $90 \%$ of what was possible in only two rehearsals.

The way we worked on this composition was different from many other intercultural contemporary pieces. We did not start by laying out each part song by song, or to choose a common song to perform with the instruments of the three different musical cultures, or tune the traditional instruments into a Western scale for the convenience of now having an accordion and a violin in the ensemble. We sought hard to find a musical key for which the accordion could play a chord for the ambience while the Pi was playing the introduction of Nora. Each ensemble chose its own song(s) to portray one aspect of the story of the Goddess, but since the Phase Two ensemble would not perform in the temple space of the Goddess, the music needed a goddess to be in the performance.

The Dance of the Three Cultures. Prof. Pornrat Damrhung provided the innovative idea of adding the dance of a goddess to the performance after she had seen the fruits of the ensemble's rehearsals. Dr. Thanaporn Saen-ai was chosen to be our dancer since she had classical training but also some knowledge of Northern folk dance and Nora dance, too. She had been working with us in this intercultural and contemporary arena for several years and so was familiar with our working style and goals. Her dance, although largely improvised, sought to blend the three cultures into one. She sought to blend Rong Ngeng, Chinese, and Nora into a set of choreographed movements by choosing the most distinguish movements of each culture, and then linking them to one other in an infinite loop as she flowed through the thrilling highlights of the composition, interacting with the song sand with the musicians. Although she only rehearsed a few times with the music ensemble, her performance turned out so beautiful, lively, fun, and offered a very harmonizing sensibility to the piece.

\subsection{Phase Two Performances}

On August 20-26, 2017, Phase Two of the project ended in performances of the new "Hoamroang Sam Prasarn" in Bangkok. The ensemble rehearsed together again in Songkhla on August 19, and then they came up together from the South on August 22. They were able to rehearse together on August 23 before performing for a selective audience on that evening, before their formal performance on the evening of August 24 at the Sodsai Pantoomkomol Centre for Dramatic Arts at Chulalongkorn University. Their performance was one of 
a set of showcase pieces of the results of some of the performance research projects done in the first year of the Thailand Research Fund project. Then on the afternoon of August 26, the ensemble performed again for the Thailand Research Fund Conference held in Paragon Mall. Each of these performances was well-received by their respective audiences, but each one was unique.

\section{$9 \quad$ Conclusion}

The heart of the "Hoamroang Sam Prasarn" composition was its musicians in both phases of its development. The best music composer or director is nothing without musicians who provide their vital charismatic quality: skilled, good, and right for the task. The same is true for the art of dancing.

What is "skilled, good, and right"? "Skilled" means talented, well-trained with musicality, and highly knowledgeable in one's own tradition. "Good" means good-hearted, passionate, focused, with kindness and understanding towards other artists, and with respect for audience. "Right for the task" means having the qualities of open-mind, good judgment to screen out what is bad for the tradition, flexible in applying one's knowledge on the work to support and promote the traditional arts to be reachable for contemporary audience, and ready and willing to pass on their knowledge and experience to others and to younger artists.

The "Hoamroang Sam Prasan" is a work of artistic research, but it is more than just a project for scholars. Its musical impact is not only found in its performances. Its performances were not the main results of this type of work. The musicians and the dancer in the ensembles for both Phase One and Phase Two of the project have transmitted their musical adventures to others. They continue to contribute this most valuable embodied and felt knowledge to others - whether young or old, musician or audience-and they continue to create this kind of work and to give new breath to the harmonies available in these traditional arts, so they can live and resonate in the future, too. ${ }^{9}$ By providing opportunities for traditional musicians to work on their own terms using the power of their own musical abilities and to do so through intercultural collaboration - in a mode I call "conservative contemporary music" - both artists and audiences are better able to appreciate the vitality of different musical traditions and their lively interactions more fully. That is a type of performance which can survive in the intercultural performance ecology of its own making.

9 Master Yusoh Umar sadly passed away unexpectedly on December 7, 2019. 


\section{Supplementary Material}

Supplementary material is available online at https://www.doi.org/10.6o84/ mg.figshare.14465229

\section{References}

Binson, Bussakorn. 2011. Dontri phaktai: Silapin kanthaithot khwamru phithikam lae khwamchuea (On Folk Music and Related Rituals and Beliefs of Southern Thailand). Bangkok: Chulalongkorn University. (In Thai).

Nikomrat, Thammanit. 2011. Nora: ramphuenthan saitrakunkhun upathamnarakon (phum thewa) (Nora: Fundamental Dance in Khun Uppathum Narakorns Line (Phum Theva)). Faculty of Fine and Applied Arts. Songkhla: Thaksin University Press. (In Thai).

Nikomrat, Thammanit. 2019. Karnbhattana Karn Sadaeng. Hoamroang Sam Prasarn Wattanatham Chumchon Phark Tai (Hoamroang Sam Prasarn: The Development of Hybrid Performance of Three Cultural Communities of the Southern Region). In Pornrat Damrhung, et al., eds. Kham sat kham wela: wicai kan sadaeng nai withi niwet watthanatham (Cross-Disciplines, Cross-Times: Performance Research in a Cultural Ecology Approach), 57-113. Nontaburi: Parbpim. (In Thai).

Pidokrat, Narongchai. 2011. Manutsaya dontri witthaya dontri phuenban phaktai (Ethnomusicology: Southern Folk Music). Wittayalai Duriyangkhasin, Mahidol University. (In Thai).

Temperley, Nicholas. 2019. "Overture." Grove Music Online, Deane Root, et al., eds. https://www.oxfordmusiconline.com/grovemusic/view/10.1093/gmo/978156159 2630.001.00o1/omo-9781561592630-e-ooooo2o616 [accessed November 21, 2019].

Royal Institute. 2011. Dictionary of the Royal Institute B.E. 2554. https://dictionary.apps. royin.go.th/. (In Thai). 